\title{
Comparison of human papillomavirus (HPV) detection in urine and cervical swab samples using the HPV GenoArray Diagnostic assay
}

Pornjarim Nilyanimit ${ }^{1}$, Jira Chansaenroj ${ }^{1}{ }^{4}$ Anant Karalak ${ }^{2}$, Piyawat Laowahutanont ${ }^{3}$, Pairoj Junyangdikul ${ }^{4}$ Yong Poovorawan ${ }^{\text {Corresp. } 1}$

1 Department of Pediatrics, Faculty of Medicine, Chulalongkorn University, Bangkok, Thailand

2

3 Department of Gynecology, National Cancer Institute, Bangkok, Thailand

4 Department of Pathology, Samitivej Srinakarin Hospital, Bangkok Hospital Group, Bangkok, Thailand

Corresponding Author: Yong Poovorawan

Email address: Yong.P@chula.ac.th

Human papillomavirus (HPV) is the leading cause of cervical cancer. Urine-based HPV testing offers a simple and non-invasive method because of its increasing acceptance. A total of 164 pairs of cervical swab and urine samples from Thai women who underwent cervical cancer screening were used for HPV testing with HPV GenoArray Diagnostic Kits. The overall concordance percentage for HPV detection in the cervical swab and urine samples was $65.2 \%$. The HPV genotypes most commonly detected were HPV16 and HPV18. An analysis of the urine samples and a second analysis of the cervical swab samples showed that the differences in the overall HPV detection rate between women with normal and abnormal cytology were not significant $(p>0.05)$. Urine samples processed with the GenoArray assay is an alternative for women who decline to undergo Pap smear even though it is not ideal as the first-line screening option. 
1 Comparison of human papillomavirus (HPV) detection in urine and cervical swab samples

2 using the HPV GenoArray Diagnostic assay

3 Pornjarim Nilyanimit ${ }^{1}$, Jira Chansaenroj ${ }^{1}$, Anant Karalak $^{2}$, Piyawat Laowahutanont ${ }^{3}$, Pairoj

4 Junyangdikul ${ }^{4}$, Yong Poovorawan ${ }^{1 *}$

5 Author Details

$6{ }^{1}$ Center of Excellence in Clinical Virology, Department of Pediatrics, Faculty of Medicine,

7 Chulalongkorn University, Bangkok, Thailand

$8{ }^{2}$ Department of Pathology, National Cancer Institute, Bangkok, Thailand

$9{ }^{3}$ Department of Gynecology, National Cancer Institute, Bangkok, Thailand

$10{ }^{4}$ Department of Pathology, Samitivej Srinakarin Hospital, Bangkok Hospital Group, Bangkok,

11 Thailand

12 Running Head: HPV detection in urine using GenoArray

13 Keywords: HPV, genotyping, cervical cancer, urine

14 *Corresponding author: Prof. Yong Poovorawan

15 E-mail: Yong.P@chula.ac.th 


\section{ABSTRACT}

17 Human papillomavirus (HPV) is the leading cause of cervical cancer. Urine-based HPV testing

18 offers a simple and non-invasive method because of its increasing acceptance. A total of 164 pairs

19 of cervical swab and urine samples from Thai women who underwent cervical cancer screening

20 were used for HPV testing with HPV GenoArray Diagnostic Kits. The overall concordance

21 percentage for HPV detection in the cervical swab and urine samples was $65.2 \%$. The HPV

22 genotypes most commonly detected were HPV16 and HPV18. An analysis of the urine samples

23 and a second analysis of the cervical swab samples showed that the differences in the overall

24 HPV detection rate between women with normal and abnormal cytology were not significant $(p>$

25 0.05). Urine samples processed with the GenoArray assay is an alternative for women who

26 decline to undergo Pap smear even though it is not ideal as the first-line screening option. 
INTRODUCTION

Human papillomavirus (HPV) causes cervical cancer (Koutsky, 1997). Approximately 170

genotypes have been identified (De Villiers et al., 2004) and at least 40 genotypes infect the human anogenital tract (De Villiers, 2013). The genital HPVs are classified into high-risk and low-risk genotypes depending on their association with uterine cervical cancer (Muñoz et al., 2003). The high-risk genotypes most commonly detected in uterine cervical cancer are HPV16, $18,31,33,35,45,52,58,39,51,56$, and 59 (Bouvard et al., 2009).

The incidence of cervical cancer in young women is increasing in many countries due to improved awareness and testing. HPV prevalence in Asia, Africa, Europe and South America varied significantly depending on the population and geographical regions (Clifford et al., 2005). In Europe, it ranges from 1.4\% (Spain) to 9.2\% (Italy). In South America, the prevalence ranged from $11.9 \%$ (Chile) to $16.3 \%$ (Argentina). In Southeast Asia, the prevalence ranged from 1.6\% (Vietnam) to $13.3 \%$ (Korea). Even within a country such as Thailand, HPV prevalence can vary from $7.2 \%$ in northern region to $15.1 \%$ in central region (Kantathavorn et al., 2015).

The Papanicolaou (Pap) test is a cost-effective way to screen for cervical cancer. Test results help physicians detect precancerous lesions and determine the course of treatment. Pap test has been shown to reduce the incidence of mortality from cervical cancer (Mählck et al., 1994). However, it is primarily used for detecting invasive cervical cancer and cannot identify asymptomatic HPV infection (Safaeian et al., 2007; Leyden et al., 2005). In addition, barriers to testing include the lack of information, personal preference, fear, embarrassment and lack of trust in healthcare under certain circumstances. False information regarding the procedure, the lack of spousal support towards screening, cultural taboos, and stigmatization of women with cervical 
50 supplementary HPV DNA assays are often required in combination with the traditional Pap smear

51 test (Cox et al., 1995).

52 HPV DNA detection in urine samples presents a feasible alternative to HPV DNA detection in cervical specimens. Urine testing provides an especially simple, non-invasive method for

54 screening (Prusty et al., 2005). The benefits of using urine for HPV DNA detection have been evaluated in disease surveillance and screening for cervical cancers involving specific genotypes.

HPV DNA urine testing can be used to identify abnormal cells in adolescent girls and young women who do not wish to have a vaginal examination (Vorsters et al., 2014; Enerly et al., 2013). Some studies have reported a high HPV detection sensitivity for urine-based assays

59 (Forslund et al., 1993; Hagihara et al., 2016; Bernal et al., 2014), while other studies have reported a low HPV detection sensitivity from urine-based assays (D'Hauwers et al., 2007; Nilyanimit et al., 2013). Husman et al., 1995), the INNO-LiPA HPV Assay (Van Hamont et al., 2006), and the Hybrid Capture 2 test (HCII) assay (Kubota et al., 1998). In addition, the HPV GenoArray Diagnostic

Kit (Hybribio Ltd., Sheung Wan, Hong Kong) is a recently developed PCR-based HPV genotyping assay, which uses L1 consensus primers to amplify $21 \mathrm{HPV}$ genotypes. It is then followed by flow-through hybridization with immobilized genotype-specific probes. This test is currently used in several hospitals in China (Liu et al., 2010). A previous study showed that the sensitivity of the HPV GenoArray assay was $97.8 \%$ and the specificity was $100 \%$. (Juan et al., 2013). If its use expanded to other parts of Asia where individuals share similar cultural beliefs, more women would benefit from increased cervical cancer screening. This study aimed to evaluate the use of a urine-based assay as a non-invasive method for HPV detection and to genotype the samples using the HPV GenoArray assay in a Thai population. 


\section{MATERIALS \& METHODS}

75 The research protocol was approved by the Ethics Committee of the National Cancer Institute,

76 Thailand (number EC COA 037/2012), and the Institutional Review Board of the Faculty of

77 Medicine at Chulalongkorn University (number 389/2555). The objective of the study was explained to the patients, and written consent was obtained from all participants. Each specimen

79 was sent for testing anonymously, which only included participant-specific numerical code and 80 age information.

\section{Clinical specimens}

82 All patients underwent the Pap smears test and were subsequently asked to participate in this 83 study. In all, 164 women consented and were willing to provide paired specimens (a Pap smear 84 sample from the cervix and a first-void urine sample). All specimen were recruited between

85 March to December 2014. Specimens were classified into three groups: 95 samples indicating 86 normal cytology, 50 samples indicating low-grade squamous intraepithelial lesions (LSIL), and

8719 samples indicating high-grade squamous intraepithelial lesions (HSIL). The ages of the 88 patients enrolled in this study were between 19 and 69 years.

\section{Sample preparation}

90 Each Pap smear sample (which are the standard samples for HPV genotyping) was evaluated by a

91 specialized cytotechnologist and the results were confirmed by a pathologist. Samples were 92 suspended in the liquid-based cytology (LBC) buffer (ThinPrep, Hologic, Marlborough, MA, 93 USA). Collection of the first-void urine (FVU) samples was performed in a sterile Cell PrepPlus 94 (Biodyne, Gyeonggi-do, Korea) urine bottle, stored at $4{ }^{\circ} \mathrm{C}$, and processed within 3 days. For 95 each sample, approximately $15 \mathrm{~mL}$ of LBC and FVU were centrifuged at 3,000 rpm for $5 \mathrm{~min}$, 96 and the supernatant was removed. The residual $800 \mu \mathrm{L}$ of the sample suspension containing cell 
97 debris was washed and centrifuged at $8,000 \mathrm{rpm}$ for $5 \mathrm{~min}$. The DNA was extracted from the

98 pellets using a DNA Prep Kit (Chaozhou Hybribio Biochemistry Ltd., Guangdong, China) and

99 stored at $-20^{\circ} \mathrm{C}$ until testing.

100 HPV GenoArray Diagnostic Assay

101 The extracted DNA from the cervical swab and urine samples was subjected to an HPV

102 genotyping assay using HPV GenoArray Diagnostic Kits (Hybribio Ltd., Sheung Wan, Hong

103 Kong) according to the manufacturer's instructions. This PCR-based assay enables the

104 amplification of $21 \mathrm{HPV}$ genotypes including 13 high-risk types (HPV 16, 18, 31, 33, 35, 39, 45,

105 51, 52, 56, 58, 59, and 68), two probable high-risk types (HPV 53 and 66), and six low-risk or

106 unknown risk types (HPV 6, 11, 42, 43, 44, and CP8304 [HPV-81]). This assay uses an L1

107 consensus primer-based PCR and is different from the Linear Array HPV Genotyping Test, which

108 uses MY09 and MY11 primers (Liu et al., 2010). After PCR amplification, the amplicons were

109 subjected to flow-through hybridization on a nylon membrane covered in immobilized HPV

110 genotype-specific oligonucleotide probes. The hybrids were detected by the addition of

111 streptavidin-horseradish peroxidase conjugate and substrate (NBT/BCIP). The presence of a

112 positive result for the internal control and the biotin dots within the membrane serves to validate

113 DNA quality, good enzyme conjugate, and successful hybridization process. Results were

114 manually interpreted using the manufacturer's guidelines. The normal detection limit is $\sim 500$

115 copies/ $\mu \mathrm{L}$ of target HPV DNA. There were no cross-reactivities from the amplification/detection

116 of the $21 \mathrm{HPV}$ genotypes. The provided positive control and two negative controls (including

117 HPV-negative C33-A cells) were included in each set of PCR to assess the performance of the 118 test.

119 Statistical methods 
120 A statistical analysis was performed using SPSS version 17.0 (SPSS Inc., Chicago, IL, USA).

121 Pearson's chi-square test for matched pairs was used to compare the performance of the two types

122 of samples regarding the detection of HPV genotypes. Statistical significance was defined as $123 p<0.05$. 
124

125

126

127

128

129

130

131

132

133

134

135

136

137

138

\section{RESULTS}

The mean age of the 164 participants was 45.8 years. Among the women with normal cytology, the mean age was 50.5 years, while among those with abnormal cytology (LSIL or HSIL), the mean age was 41.1 years. Results from the cervical swab samples showed that $39.6 \%(65 / 164)$ were HPV DNA-positive (Table 1). In total, 11\% (18/164) contained multiple HPV genotypes. The most common HPV genotypes detected were HPV16 (12 samples) and HPV18 (8 samples). Thus, $12.2 \%$ (20/164) contained either HPV16 or HPV18. In the normal cytology group, 11 of the 95 samples (11.6\%) were HPV DNA-positive. In contrast, the LSIL and HSIL groups had 35 (10.0\%) and 19 (100.0\%) HPV DNA-positive samples, respectively.

For the urine samples, $32.3 \%(53 / 164)$ were HPV DNA-positive (Table 1), of which $7.9 \%$ (13/164) had multiple HPV genotypes. The most commonly detected HPV genotypes were HPV18 (17 samples) and HPV16 (four samples). In total, 12.2\% (20/164) contained HPV16 or HPV18. In the normal cytology group, 10 of the 95 samples (10.5\%) were HPV DNA-positive. In contrast, the LSIL and HSIL groups had 35 (10.0\%) and 8 (42.1\%) HPV DNA-positive samples, respectively.

We next compared HPV detection efficacy between the standard Pap smear samples and the urine samples. Comparison between the cervical swab and urine specimen resulted in the overall concordance of $65.2 \%(107 / 164)$ (Table 1). In the normal cytology group, the concordance was $71.6 \%(68 / 95)$. In the abnormal cytology group, the concordance was $56.5 \%(39 / 69)$. Using the Pap smear results as reference, the sensitivity and specificity of the urine-based HPV GenoArray Detection Kit were $56.5 \%$ and $70.6 \%$, respectively. However, these results were lower than other studies (Table 2). The positive and negative predictive values were $53.8 \%(95 \% \mathrm{CI}=41.9$ to $65.4)$ and $72.7 \%(95 \% \mathrm{CI}=63.2$ to 80.5$)$, respectively.

For multiple HPV infections, the cervical swab-based assays were able to detect more HPV genotypes in each sample. However, in the normal cytology group, for each pair of biospecimens, 
149 the most common number of genotypes per sample was one. Similarly, in the abnormal cytology 150 group, 36 of the 69 cervical swab samples (52.2\%) and 31 of the 69 urine samples (44.9\%) had a 151 single genotype (Table 3).

152 An analysis of the urine samples and a second analysis of the cervical swab samples

153 showed that the differences in the overall HPV detection rate between the normal and abnormal 154 cytology groups were not significant $(p>0.05)$. 


\section{DISCUSSION}

156 Despite the benefits offered by the Pap test, screening attendance remains low (Gakidou et al., 157 2008), while the estimated incidence of invasive cervical cancer remains high (Leyden et al., 158 2005). In Thailand, 25-38\% of women aged 30-65 years have had only one Pap test (Sriamporn 159 et al., 2006). When cervical testing for HPV is required, these results suggest that urine sample 160 collection provides an alternative non-invasive sampling method for monitoring HPV infection in 161 women. In a previous study, the overall percentage agreement between HPV detection in urine 162 and cervical samples was 88\% using Cobas 4800 HPV test (Bernal et al., 2014), 75\% using 163 electrochemical DNA chip (Nilyanimit et al.,2013) and, in this study, the percentage was $65.2 \%$.

164 The undeniable advantage in testing urine sample is its acceptance and convenience for the 165 patients, although better results are obtained with first urine in the morning (Vorsters et al., 2014).

166 However, the results must be interpreted with caution owing to variations among the studies in 167 terms of the participant characteristics, surrogate nature of using cervical HPV detection to screen 168 for cervical disease, and lack of standardized urine testing methods.

169 Urine sample assays cannot be used to detect all of the genital HPV infections, but these assays provide an alternative for use in epidemiological surveys in which invasive sampling is

171 difficult to perform. Under these circumstances, testing urine for HPV DNA offers a distinct advantage (Prusty et al., 2005). Previous studies have compared HPV detection rates between

173 cervical and urine samples in order to evaluate the ability of urine-based assays to detect the 174 prevalence of HPV independently of cervical cytology assays (Daponte et al., 2006; Munoz et 175 al., 2013). Evidence suggests that the sensitivity of urine testing for HPV 16 and 18 was higher 176 for participants with cervical cancer (88.8\%) than for those with high- and low-grade lesions 177 (Daponte et al., 2006). However, since our samples comprised more of normal than abnormal 178 cytology, proportion of HPV16-positive samples are thus admittedly lower in this study. The 179 larger-scale HPV genotyping for cervical cancer screening in China showed the most common 
180 high risk HPV genotypes in women population worldwide were HPV16, 18, 31, 58, 52, 51 and

18133 , however frequencies varied by region (de Sanjosé et al., 2007). In contrast, some regions

182 showed that HPV52 is higher detection than HPV16 because of the geographical and biological

183 interaction between HPV genotypes and host immunogenic factors (de Sanjosé et al., 2007; Ye et

$184 a l ., 2010)$. Alternatively, it is possible that certain urine samples yield low-efficiency

185 amplification due to the presence of inhibitory substances in the urine or HPV DNA loss during

186 processing (Brinkman et al., 2004).

187 The HPV DNA analysis of urine samples needs to be developed further before a urine-based

188 assay can replace the Pap smear test. It is possible that a greater amount of urethral cells in the

189 urine samples helped to increase the sensitivity of the test. An analysis of the urine samples and a

190 second analysis of the cervical swab samples showed that the differences in the overall HPV

191 detection rate between women with normal and abnormal cytology were not significant $(p>$

192 0.05). This result suggests that urine represents a viable substitute for cervical swabs. However,

193 the urine samples should be optimized by preventing DNA degradation during extraction and

194 storage, recovering cell-free HPV DNA in addition to cell-associated DNA, processing a

195 sufficient volume of urine, and collecting the first portion of the urine stream in the morning

196 (Vorsters et al., 2014).

197 Using traditional cytological analysis, it is difficult to determine accurate screening results for

198 HPV-associated anogenital tumors. Therefore, HPV genotyping is an alternative screening

199 method to be used in combination with traditional cytology for identifying patients at high risk of

200 developing squamous cell carcinoma (Saslow et al., 2012; WHO, 2013). Nowadays, there are

201 many HPV genotyping techniques for detecting HPV DNA, such as PCR, real-time PCR,

202 restriction fragment length polymorphism (RFLP), Hybrid Capture, and Linear Array (Bernard et

203 al., 1994; Cox et al., 1995; Castle et al., 2008). However, PCR and real-time PCR need specific

204 expensive equipment (such as a thermal cycler), and these methods have not yet become common 
205 procedures in hospital laboratories (Hagiwara et al., 2007). This study used the HPV GenoArray

206 Diagnostic Kit for HPV genotyping, which is a commercial kit that has recently been started to be 207 used, especially in China (Liu et al., 2010). The results from the HPV GenoArray assay used in 208 this study were a percentage-point (39.6\%) higher compared to the results from a previous survey 209 of Thai women (7.6\%) (Chansaenroj et al., 2010) and one of Japanese women (22.5\%) (Onuki et 210 al., 2009). The higher percentage may be due to the small number of participants in our study 211 sample.

212 The Linear Array HPV Genotyping Test has been widely used as a standard reference method 213 for evaluating new methods. However, the HPV GenoArray Diagnostic Kit is an alternative 214 technique for studies conducted in resource-limited laboratories because the cost of the HPV 215 GenoArray Diagnostic Kit is lower than that of the Linear Array HPV Genotyping Test and the 216 hybridization time is also lower (Li et al., 2012; Liu et al., 2010). Moreover, the HPV GenoArray 217 assay can distinguish and identify HPV 52, which is one of the most common high-risk HPV 218 genotypes in women in eastern and southeastern Asia (Sukvirach et al., 2003; Takehara et al., 219 2011).

220 In conclusion, the HPV GenoArray assay is an alternative for HPV genotyping using both 221 cervical swab and urine samples, the latter of which is an alternative for women declining to undergo Pap smear. Although it is not the gold standard, utilization of this method is expected to will be increase the number of women who undergo cervical cancer screening.

\section{ACKNOWLEDGEMENTS} assistance.

\section{Funding}


228 This work was supported by the National Research Council of Thailand, the Research Chair

229 Grant from NSTDA, the Center of Excellence in Clinical Virology (GCE 59-009-30-005) and

230 King Chulalongkorn University, the Centenary Academic Development Project (CU56-HR01),

231 the Ratchadaphiseksomphot Endowment Fund of Chulalongkorn University (RES560530093),

232 Office of Higher Education Commission (NRU 59-002-HR) and Dutsadi Piphat Scholarship.

233 Grant Disclosures

234 The National Research Council of Thailand

235 The Research Chair Grant from NSTDA

236 The Center of Excellence in Clinical Virology (GCE 59-009-30-005)

237 The Centenary Academic Development Project (CU56-HR01)

238 The Ratchadaphiseksomphot Endowment Fund of Chulalongkorn University (RES560530093)

239 Office of Higher Education Commission (NRU 59-002-HR)

240 Dutsadi Piphat Scholarship.

\section{Conflict of Interest}

242 The authors have no conflicts of interest to declare. 
243

244

245

246

247

248

249

250

251

252

253

254

255

256

257

258

259

260

261

262

263

264

265

266

\section{REFERENCES}

Bernal S, Palomares JC, Artura A, Parra M, Cabezas JL, Robles A, Martín

Mazuelos E. 2014. Comparison of urine and cervical samples for detecting human papillomavirus (HPV) with the Cobas 4800 HPV test. J Clin Virol 61:548-552

DOI 10.1016/j.jcv.2014.10.001.

Bernard HU, Chan SY, Manos MM, Ong CK, Villa LL, Delius H, Peyton CL, Bauer HM, Wheeler CM. 1994. Identification and assessment of known and novel human papillomaviruses by polymerase chain reaction amplification, restriction fragment length polymorphisms, nucleotide sequence, and phylogenetic algorithms. J Infect Dis 170:10771085 PubMed PMID 7963696.

Bouvard V, Baan R, Straif K, Grosse Y, Secretan B, El Ghissassi F, Benbrahim-Tallaa L, Guha N, Freeman C, Galichet L, Cogliano V. 2009. WHO International Agency for Research on Cancer Monograph Working Group. A review of human carcinogens--Part B: biological agents. Lancet Oncol 10:321-322 PubMed PMID 19350698.

Brinkman JA, Rahmani MZ, Jones WE, Chaturvedi AK, Hagensee ME. 2004. Optimization of PCR based detection of human papillomavirus DNA from urine specimens. J Clin Virol 29:230-240 PubMed PMID 15018850.

Castle PE, Gravitt PE, Solomon D, Wheeler CM, Schiffman M. 2008. Comparison of linear array and line blot assay for detection of human papillomavirus and diagnosis of cervical precancer and cancer in the atypical squamous cell of undetermined significance and lowgrade squamous intraepithelial lesion triage study. J Clin Microbiol 46:109-117 PubMed PMID 17989194.

Chansaenroj J, Lurchachaiwong W, Termrungruanglert W, Tresukosol D, Niruthisard S, Trivijitsilp P, Sampatanukul P, Poovorawan Y. 2010. Prevalence and genotypes of 

PMID 20593940.

\section{Clifford GM, Gallus S, Herrero R, Muñoz N, Snijders PJ, Vaccarella S, Anh PT, Ferreccio} C, Hieu NT, Matos E, Molano M, Rajkumar R, Ronco G, de Sanjosé S, Shin HR, Sukvirach S, Thomas JO, Tunsakul S, Meijer CJ, Franceschi S. 2005. IARC HPV Prevalence Surveys Study Group. Worldwide distribution of human papillomavirus types in cytologically normal women in the International Agency for Research on Cancer HPV prevalence surveys: a pooled analysis. Lancet 366:991-998 PubMed PMID 16168781.

Cox JT, Lorincz AT, Schiffman MH, Sherman ME, Cullen A, Kurman RJ. 1995. Human papillomavirus testing by hybrid capture appears to be useful in triaging women with a cytologic diagnosis of atypical squamous cells of undetermined significance. Am J Obstet Gynecol 172:946-954 PubMed PMID 7892889.

Cuschieri K, Nandwani R, McGough P, Cook F, Hogg L, Robertson C, Cubie H. 2011. Urine testing as a surveillance tool to monitor the impact of HPV immunization programs. $J$ Med Virol 83:1983-1987 DOI 10.1002/jmv.22183.

\section{Daponte A, Pournaras S, Mademtzis I, Hadjichristodoulou C, Kostopoulou E,} Maniatis AN, Messinis IE. 2006. Evaluation of high-risk human papillomavirus types PCR detection in paired urine and cervical samples of women with abnormal cytology. $J$ Clin Virol 36:189-193 PubMed PMID 16690350.

\section{De Roda Husman AM, Walboomers JM, van den Brule AJ, Meijer CJ, Snijders PJ. 1995.} The use of general primers GP5 and GP6 elongated at their 3' ends with adjacent highly conserved sequences improves human papillomavirus detection by PCR. J Gen Virol 76:1057-1062 PubMed PMID 9049358.

De Sanjosé S, Diaz M, Castellsagué X, Clifford G, Bruni L, Muñoz N, Bosch FX. 2007. Worldwide prevalence and genotype distribution of cervical human papillomavirus DNA in 

17597569.

294

295

296

297

De Villiers EM, Fauquet C, Broker TR, Bernard HU, zur Hausen H. 2004. Classification of papillomaviruses. Virology 324:17-27 PubMed PMID 15183049.

De Villiers EM. 2013. Cross-roads in the Classification of papillomaviruses. Virology 445:2-10. DOI 10.1016/j.virol.2013.04.023.

\section{D'Hauwers K, Depuydt C, Bogers JP, Stalpaert M, Vereecken A, Wyndaele JJ,} Tjalma W. 2007. Urine versus brushed samples in human papillomavirus screening: study in both genders. Asian J Androl 9:705-710 PubMed PMID 17712490.

Enerly E, Olofsson C, Nygård M. 2013. Monitoring human papillomavirus prevalence in urine samples: a review. Clin Epidemiol 5:67-79 DOI 10.2147/CLEP.S39799.

Forslund O, Hansson BG, Rymark P, Bjerre B. 1993. Human papillomavirus DNA in urine samples compared with that in simultaneously collected urethra and cervix samples. $J$ Clin Microbiol 31:1975-1979 PubMed PMID 8396581.

Gakidou E, Nordhagen S, Obermeyer Z. 2008. Coverage of cervical cancer screening in 57 countries: low average levels and large inequalities. PLoS Med 5:e132 DOI 10.1371/journal.pmed.0050132.

\section{Gupta A, Arora R, Gupta S, Prusty BK, Kailash U, Batra S, Das BC. 2006. Human} papillomavirus DNA in urine samples of women with or without cervical cancer and their male partners compared with simultaneously collected cervical/penile smear or biopsy specimens. J Clin Virol 37:190-194 PubMed PMID 16931139.

\section{Hagihara M, Yamagishi Y, Izumi K, Miyazaki N, Suzuki T, Kato H, Nishiyama N, Koizumi} Y, Suematsu H, Mikamo H. 2016. Comparison of initial stream urine samples and cervical samples for detection of human papillomavirus. $J$ Infect Chemother 22:559-562 DOI 10.1016/j.jiac.2016.05.009. 
317

318

319

320

321

322

323

324

325

326

327

328

329

330

331

332

333

334

335

336

337

338

339

Hagiwara M, Sasaki H, Matsuo K, Honda M, Kawase M, Nakagawa H. 2007. Loop-

mediated isothermal amplification method for detection of human papillomavirus type 6 , 11,16, and 18. J Med Virol 79:605-615 PubMed PMID 17385684.

Juan Du, Xiaonian Lu, Jun Liang, Yongsheng Yang, Jinran Lin, Xiaohua Zhu and Jinhua Xu. 2013. Detection and typing of human papillomavirus (HPV) in condyloma acuminatum and bowenoid papulosis HybriBio HPV GenoArray test kit, real-time polymerase chain reaction (PCR) and sequencing. Afr J Pharm Pharmacol 7:73-77 DOI 10.5897/AJPP12.482.

Kantathavorn N, Mahidol C, Sritana N, Sricharunrat T, Phoolcharoen N, Auewarakul C, Teerayathanakul N, Taepisitpong C, Saeloo S, Sornsamdang G, Udomchaiprasertkul W, Krongthong W, Arnamwong A. 2015. Genotypic distribution of human papillomavirus (HPV) and cervical cytology findings in 5906 Thai women undergoing cervical cancer screening programs. Infect Agent Cancer 10:7 DOI 10.1186/s13027-015-0001-5.

Koutsky L. 1997. Epidemiology of genital human papillomavirus infection. Am J Med 102:3-8 PubMed PMID 9217656.

Kubota T, Ishi K, Suzuki M, Utsuno S, Igari J. 1998. Usefulness of hybrid capture HPV DNA assay as a diagnostic tool for human papillomavirus infection. Kansenshogaku Zasshi 72:1219-1224 PubMed PMID 9884509.

Leyden WA, Manos MM, Geiger AM, Weinmann S, Mouchawar J, Bischoff K, Yood MU, Gilbert J, Taplin SH. 2005. Cervical cancer in women with comprehensive health care access: attributable factors in the screening process. J Natl Cancer Inst 97:675-683 PubMed PMID 15870438. 
340

341

342

343

344

345

346

347

348

349

350

351

352

353

354

355

356

357

358

359

360

361

362

363

Li J, Mei J, Wang X, Hu L, Lin Y, Yang P. 2012. Human papillomavirus type-specific prevalence in women with cervical intraepithelial neoplasm in Western China. J Clin Microbiol 50:1079-1081. DOI 10.1128/JCM.06214-11.

Liu SS, Leung RC, Chan KK, Cheung AN, Ngan HY. 2010. Evaluation of a newly developed GenoArray human papillomavirus (HPV) genotyping assay and comparison with the Roche Linear Array HPV genotyping assay. J Clin Microbiol 48:758-64 DOI 10.1128/JCM.00989-09.

Mählck CG, Jonsson H, Lenner P. 1994. Pap smear screening and changes in cervical cancer mortality in Sweden. Int J Gynaecol Obstet 44:267-272 PubMed PMID 7909766.

Munoz M, Camargo M, Soto-De Leon SC, Sanchez R, Parra D, Pineda AC, Sussmann O, Perez-Prados A, Patarroyo ME, Patarroyo MA. 2013. Human papillomavirus detection from human immunodeficiency virus-infected Colombian women's paired urine and cervical samples. PLoS One 8:e56509 DOI 10.1371/journal.pone.0056509.

Muñoz N, Bosch FX, de Sanjosé S, Herrero R, Castellsagué X, Shah KV, Snijders PJ, Meijer CJ. 2003. International Agency for Research on Cancer Multicenter Cervical Cancer Study Group. Epidemiologic classification of human papillomavirus types associated with cervical cancer. $N$ Engl J Med 348:518-527 PubMed PMID 12571259

Nilyanimit P, Wanlapakorn N, Niruthisard S, Pohthipornthawat N, Karalak A, Laowahutanont P, Phanuphak N, Gemma N, Poovorawan Y. 2013. Detection of human papillomavirus in male and female urine by electrochemical DNA chip and PCR sequencing. Asian Pac J Cancer Prev 14:5519-5525 PubMed PMID 24175852.

Onuki M, Matsumoto K, Satoh T, Oki A, Okada S, Minaguchi T, Ochi H, Nakao S, Someya K, Yamada N, Hamada H, Yoshikawa H. 2009. Human papillomavirus infections 
364

among Japanese women: age-related prevalence and type-specific risk for cervical cancer. Cancer Sci 100:1312-1316 DOI 10.1111/j.1349-7006.2009.01161.x.

Prusty BK, Kumar A, Arora R, Batra S, Das BC. 2005. Human papillomavirus (HPV) DNA detection in self-collected urine. Int J Gynaecol Obstet 90:223-227 PubMed PMID 16043176.

Safaeian M, Solomon D, Castle PE. 2007. Cervical cancer prevention — cervical screening: science in evolution. Obstet Gynecol Clin North Am 34:739-760 PubMed PMID 18061867.

Saslow D, Solomon D, Lawson HW, Killackey M, Kulasingam SL, Cain J, Garcia FA, Moriarty AT, Waxman AG, Wilbur DC, Wentzensen N, Downs LS Jr, Spitzer M, Moscicki AB, Franco EL, Stoler MH, Schiffman M, Castle PE, Myers ER. 2012. ACS-ASCCP-ASCP Cervical Cancer Guideline Committee.. American Cancer Society, American Society for Colposcopy and Cervical Pathology, and American Society for Clinical Pathology screening guidelines for the prevention and early detection of cervical cancer. 62:147-172. DOI 10.3322/caac.21139.

Sriamporn S, Khuhaprema T, Parkin M. 2006. Cervical cancer screening in Thailand: an overview. J Med Screen 1:S39-43 PubMed PMID 17227641.

Strauss S, Jordens JZ, McBride D, Sonnex C, Edwards S, Desselberger U, Watt P, Gray JJ. 1999. Detection and typing of human papillomavirus DNA in paired urine and cervical scrapes. Eur J Epidemiol 15:537-543 PubMed PMID 10485346.

\section{Sukvirach S, Smith JS, Tunsakul S, Muñoz N, Kesararat V, Opasatian O, Chichareon S,} Kaenploy V, Ashley R, Meijer CJ, Snijders PJ, Coursaget P, Franceschi S, Herrero R. 2003. Population-based human papillomavirus prevalence in Lampang and Songkla, Thailand. J Infect Dis 187:1246-1256 PubMed PMID 12696004. 
388

389

390

391

392

393

394

395

396

397

398

399

400

401

402

403

404

405

406

407

408

409

Takehara K, Toda T, Nishimura T, Sakane J, Kawakami Y, Mizunoe T, Nishiwaki M, Taniyama K. 2011. Human papillomavirus types 52 and 58 are prevalent in uterine cervical squamous lesions from Japanese women. Patholog Res Int 2011:246936 DOI $10.4061 / 2011 / 246936$.

Van Hamont D, van Ham MA, Bakkers JM, Massuger LF, Melchers WJ. 2006. Evaluation of the SPF10-INNO LiPA human papillomavirus (HPV) genotyping test and the roche linear array HPV genotyping test. J ClinMicrobiol 44:3122-3129 PubMed PMID 16954236

\section{Vorsters A, Van den Bergh J, Micalessi I, Biesmans S, Bogers J, Hens A, De Coster I, Ieven} M, Van Damme P. 2014. Optimization of HPV DNA detection in urine by improving collection, storage, and extraction. Eur J Clin Microbiol Infect Dis 33:2005-2014 DOI $10.1007 / \mathrm{s} 10096$ 014-2147-2.

WHO. 2013. WHO guidelines for screening and treatment of precancerous lesions for cervical cancer prevention. World Health Organization, Geneva, Switzerland.

Ye J, Cheng X, Chen X, Ye F, Lü W, Xie X. 2010. Prevalence and risk profile of cervical Human papillomavirus infection in Zhejiang Province, southeast China: a populationbased study. Virol J 7:66 DOI 10.1186/1743-422X-7-66.

\section{TABLES}

Table 1. Detection of HPV genotypes and concordance between cervical swab and urine samples.

Table 2. Studies of human papillomavirus DNA detected in paired urine and cervical samples from females of all ages.

Table 3. Number of HPV genotypes detected using the HPV GenoArray assay. 


\section{Table $\mathbf{1}$ (on next page)}

Table 1. Detection of HPV genotypes and concordance between cervical swab and urine samples. 
1Table 1. Detection of HPV genotypes and concordance between cervical swab and urine 2samples.

3

\begin{tabular}{llllll}
\hline Cytology & \multicolumn{4}{c}{ Specimen (\% positive) } & \multirow{2}{c}{ Concordance } \\
& \multicolumn{2}{c}{ Any HPV positive } & \multicolumn{2}{c}{ HPV16\&18 } & \\
\cline { 2 - 5 } & Cervical swab & Urine & Cervical swab & Urine & (percentage) \\
\hline Normal (N=95) & $11(11.6)$ & $10(10.5)$ & $1(1.1)$ & $4(4.2)$ & $68(71.6)$ \\
LSIL $(\mathrm{N}=50)$ & $35(10.0)$ & $35(10.0)$ & $11(22.0)$ & $13(26.0)$ & $31(62.0)$ \\
HSIL $(\mathrm{N}=19)$ & $19(100.0)$ & $8(42.1)$ & $8(42.1)$ & $3(15.8)$ & $8(70.5)$ \\
\hline Total $(\mathrm{N}=164)$ & $65(39.6)$ & $53(32.3)$ & $20(12.2)$ & $20(12.2)$ & $107(65.2)$ \\
\hline
\end{tabular}


Page $\mathbf{2}$ of $\mathbf{2}$ 


\section{Table 2 (on next page)}

Table 2. Studies of human papillomavirus DNA detected in paired urine and cervical samples from females of all ages. 
1Table 2. Studies of human papillomavirus DNA detected in paired urine and cervical samples from females of all ages.

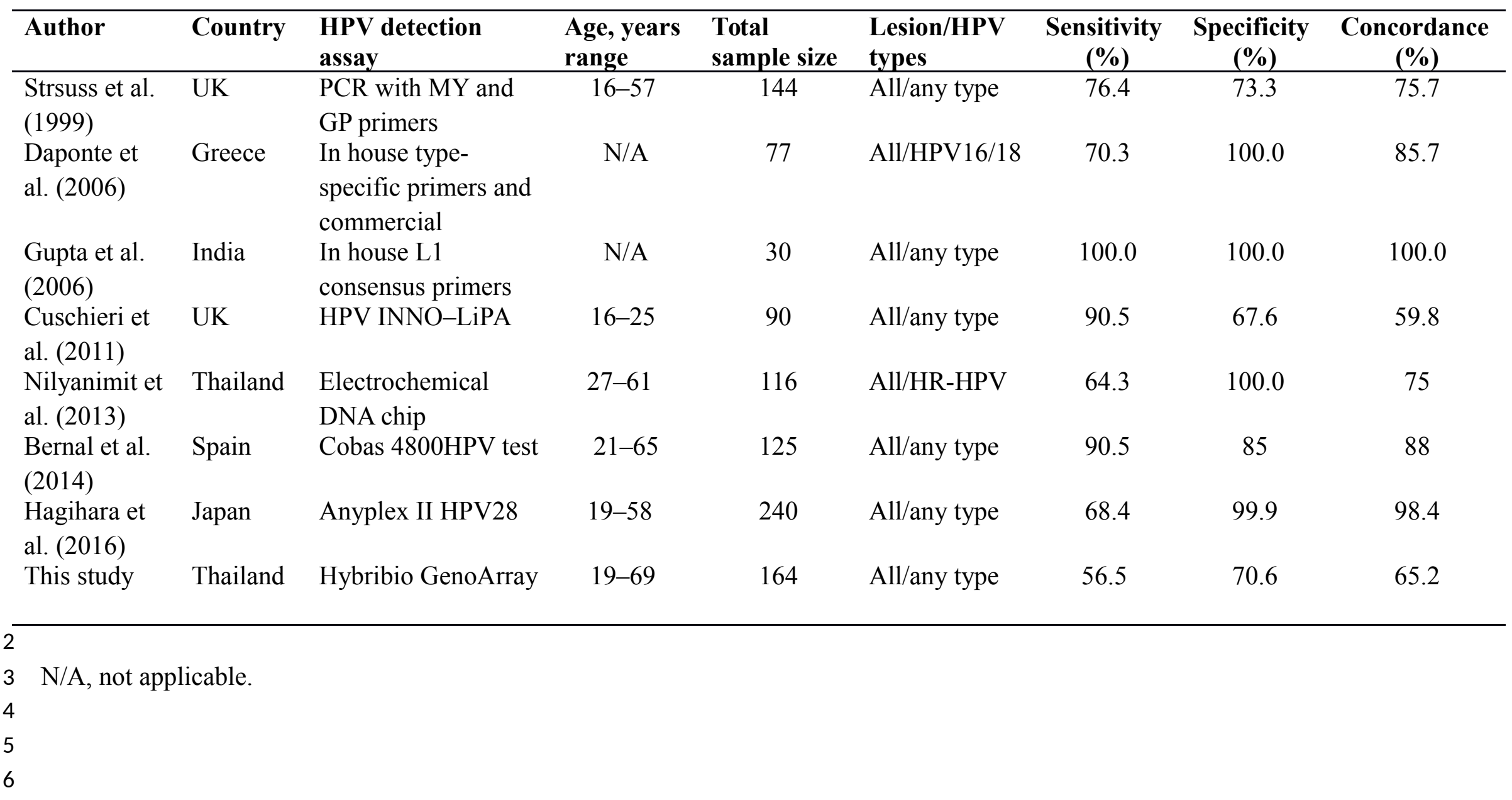




\section{Table 3(on next page)}

Table 3. Number of HPV genotypes detected using the HPV GenoArray assay.

Table 3. Number of HPV genotypes detected using the HPV GenoArray assay. 
1Table 3. Number of HPV genotypes detected using the HPV GenoArray assay.

\begin{tabular}{ccccc}
\hline No. of HPV genotypes & \multicolumn{2}{c}{ Normal (N=95) } & \multicolumn{2}{c}{ Abnormal (N=69) } \\
\cline { 2 - 5 } detected & Cervical swab & Urine & Cervical swab & Urine \\
\hline $0^{\text {a }}$ & $84(88.4)$ & $85(89.5)$ & $15(21.7)$ & $26(37.7)$ \\
1 & $11(11.5)$ & $9(9.4)$ & $36(52.2)$ & $31(44.9)$ \\
2 & - & $1(1.1)$ & $14(20.3)$ & $7(10.1)$ \\
$\geq 3$ & - & - & $4(5.8)$ & $5(7.3)$ \\
\hline
\end{tabular}

$2{ }^{\text {a }}$ samples were HPV DNA-negative

3 